\title{
Measurement of Process Parameters in Magneto-Rheological Fluid Assisted Cylindrical Surface Nano Finishing Process using Grey Relational Methods
}

\author{
Prabhu. L, Chandan jyoti patra, Raj Jawahar, Jishnu P Sajeev, Dildas, Mohammed Anas
}

\begin{abstract}
Techniques for the analysis of machining parameters on cylindrical surface finish of $304 \mathrm{~L}$ stainless steel with multiple response. It depends on quadratic pattern - (GRG) Grey Relational Grade is proposed in this paper. In this work, optimized the machining parameters such as working gap, Work-Piece Speed (WPS), and wheel speed rate and flew value are concluded the various responses such as Material Removal Rate (MRR), Normal Force $(\mathrm{F}-\mathrm{N})$, and surface roughness (Ra). Optimal process parameter is determined by Taguchi concept utilizing the GRG the performance index. And value of GRG used to recognize parameters optimum level. A antecedent of Variance (ANOVA) is used to resolve the augmentation of aspect $r$.
\end{abstract}

Keywords: Cylindrical surface finish, magneto rheological fluid, AISI 304L austenitic stainless steel, genetic algorithm, ANOVA, microstructure study.

\section{INTRODUCTION}

In the precise parts manufacturing process, the ultimate operation to finalize is concerning their workers intensive, consumption of time as well as the controllable least nature. The final finishing process in traditional has no capability to provide characteristics of surface which is needed but in some cases, this kind of processes are economically incompetent due to taking long time to process and the requirement of equipment that in high expensive one. Based on their certain purpose, it requires the lubrication wearing and them playing useful in component service life.

Revised Manuscript Received on December 30, 2019.

* Correspondence Author

L.Prabhu*, Professor, Department of Mechanical Engineering, Aarupadai veedu Institute of Technology, Vinayaka Mission's Research Foundation, Chennai, India, prabhu@avit.ac.in

Chandan Jyoti Patra, PG Scholar, Department of Mechanical Engineering, Aarupadai veedu Institute of Technology, Vinayaka Mission's Research Foundation, Chennai, India,

Raj Jawahar, Entrepreneur of Dynamechz Research Labz, India.

Jishnu P Sajeev, UG Scholar, Department of mechanical Engineering , Aarupadai veedu Institute of Technology, Vinayaka Mission's Research Foundation, Chennai

Dildas, UG Scholar, Department of mechanical Engineering , Aarupadai veedu Institute of Technology, Vinayaka Mission's Research Foundation, Chennai

Mohammed Anas, UG Scholar, Department of mechanical Engineering , Aarupadai veedu Institute of Technology, Vinayaka Mission's Research Foundation, Chennai

(C) The Authors. Published by Blue Eyes Intelligence Engineering and Sciences Publication (BEIESP). This is an open access article under the CC BY-NC-ND license (http://creativecommons.org/licenses/by-nc-nd/4.0/)
The surface finish and treatment are influenced in the low energy by strongly. Due to rough surfaces and irregular surfaces is revealing exhaustion properties, the environment of surface is an essential cause for component strength influence and the efficiency is decreased because of increment of surface roughness and increasing in optimal losses. AISI 304L stainless steel have the extensive properties like better corrosion resistance, high ductility, good spinning and excellent drawing. Low carbon content means during solder and lower sensitivity to intergranular corrosion. It is used in following application are cryogenic vessels, beer barrels, chemical equipment's, paper industry, coal and oil well filter screens, cooling coils, , flexible metal hose, food processing tools, nuclear vessels, refrigeration equipment, valves, shipping drums, textile dyeing equipment, tubing spinning. Magneto rheological finishing process is an advanced precision finishing process technology used for finishing material surfaces up to nano level. [1] Lohitaksha M Mayar investigated the Inconel 718 super alloy parameter optimization with several answers, which relate to the Taguchi orthogonal array with GRA. [2]P. Jayaraman and Maheshkumar explained the AA 6063 T6 aluminium admixture of turning based on optimization machining parameters. [3] Zahid A. Khan et al consider the chattels of Raw mean and kerf width on steel (SS 304). [4] J.B. Saiden et al studied during varied responses the effects of process parameters gets variations in their shear rate and MRR(Material Removal Rate) in wire electrode discharge machine (WEDM) operations. [5]Sunil Jhaet al studied in the (MRAFF) magneto rheological abrasive flow finishing process, the effect on pressure and roughness in amount of last cycles. [6]Ajay Sidpara, V.K. Jain says a model in theoretical that improves the in depth mechanism of understanding about the material removal by acting forces over the work piece while the finishing process of MR fluid.[7]Ajay Sidpara and V.K. Jain conducted a prediction study of process parameter effects. [8] Shai $\mathrm{N}$ et al. With the help of Magnetic Geology (MRF), we studied the precise micro-turf surfaces of tungsten carbides and found that the micro-hardening of the valley (B-V) from the surface of the micro-grinding surface with hard or medium abrasive size instruments indicates the depth of the layer. 


\section{Measurement of Process Parameters in Magneto-Rheological Fluid Assisted Cylindrical Surface Nano Finishing Process using Grey Relational Methods}

Factual depth of the distorted surface layer induced by milling is defined by MRF spots. [9] Kyung proposed a latest deferring process utilizing a magnet or heological fluid. They used more than one material removal mechanisms induced by magnetic heat flux. [10] H.B. Cheng investigated the fictional implementation of RB-SiC materials. It arises the question of magnetic resonance (MRF) of RB-SiC glass. Aspects of various glazing liquids, limitations in analysis of physical techniques, effects on the properties of some processing parameters, and accuracy of surface relative removal rates. [11] H.B. Cheng conducted an experimental investigation of optical aspheric components and showed that after 10 minutes of refinement the roughness on the top of the an be reduced from 3 to 1 nanometer.[12] VK Jain et al developed a method, Chemo-Mechanical Magnetic-Chemical accomplish (CMMRF) for silicon brighten, and it is used for magnetic-chemical finishing (MRF) and chemical mechanical polishing (CMF). B) combines both features and has no effect on the process involved. [13] F.C. Sai et al

drifting out an experimental analysis to obtain optimal processing conditions for SKD 61 axle steel abrasive jet polishing. [14]J ae-SeobKwakinc by using permanent magnet on the opposite site of work piece is done by experimental verification and the simulation is run by magnetic flux density and non ferrous materials[15] Ajay Chidbara and V.K. During the MR fluid-based finishing process, Jain performed a test trial, which is used for brittle materials ranging from optical glasses to hard crystals. [16]N Senthilkumaret al verified the shape of cutting, angle of relief and nose radius of machining parameters using Taguchi based GRA. [17] a. Sadiq and M.S. Shanmugam proposed a new method to improve the coating on non-magnetic surfaces in the process of magnetic-chemical abrasion. [18] Mamila Ravi Shankar and others performed an experimental analyze and mechanism for the removal of material in the nanoparticles of MMCs using the Abrasive Flow Termination (AFF) procedure. [19] Ajay Chitbara, V.K. Jain examined the effect of process parameters on the filling and dispersion of empty single crystalline silicon material in MRF. In this current study, work has been proposed to study the effect of varying process parameters on the cylindrical surface termination process with the help of magnetic-rheological fluid (MRF).

\section{PROPOSED SYSTEM WITH PROCEDURE}

\section{A. Material}

Austenite stainless steel (AISI 304L) cylindrical pipe of $160 \mathrm{~mm}$ outer diameter; $8 \mathrm{~mm}$ thickness and $265 \mathrm{~mm}$ length workpiece material was used for this nano level cylindrical surface finishing study. Composition of chemical content in the workpiece material is representing in Table. 1.

Table 1. Chemical architecture of work piece material (SS 304L)

\begin{tabular}{|l|l|l|l|l|l|l|l|l|l|}
\hline Material & $\mathrm{C}$ & $\mathrm{Mn}$ & $\mathrm{P}$ & $\mathrm{S}$ & $\mathrm{Si}$ & $\mathrm{Cr}$ & $\mathrm{Ni}$ & $\mathrm{Al}$ & $\mathrm{Fe}$ \\
\hline SS 304L & 0.03 & 2 & 0.045 & 0.03 & 0.75 & 20 & 12 & 0.1 & balance \\
\hline
\end{tabular}

Table 2. Selected levels and Parameters

\begin{tabular}{|l|l|l|l|}
\hline Parameters & Levels 1 & Levels 2 & Levels \\
\hline Working gap (mm) & 5 & 10 & 15 \\
\hline Workpiece rotation (rpm) & 275 & 300 & 350 \\
\hline Wheel speed (rpm) & 200 & 250 & 300 \\
\hline Deliver rate (mm/rev) & 0.1 & 0.15 & 0.2 \\
\hline
\end{tabular}

\section{B. Cylindrical surface machining}

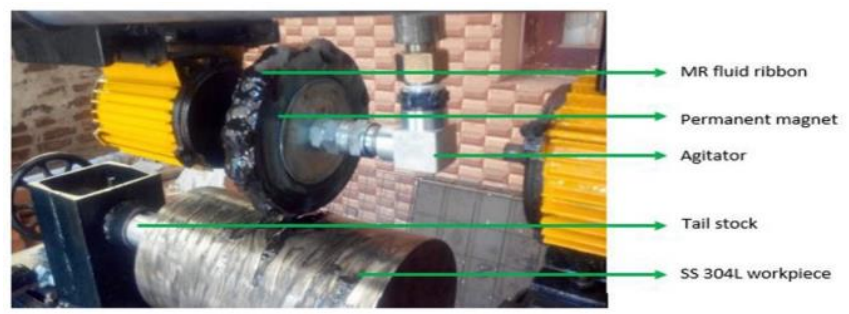

Figure 1. MR fluid cylindrical surface machining of AISI 304L stainless steel
The cylindrical surface accomplish experiments is lugged out to finish the final surface of the object up to nano level with the aid of Magneto- rheological (MR) fluid. The cylindrical finishing machine experimental setup is shown in Fig. [1]. Magneto rheological fluid composed of silicon oil with grease, CIPs (carbonyl iron particles) and Sic (silicon carbide). 
Table 3. Design of experiments and output value

\begin{tabular}{|c|c|c|c|c|c|c|c|}
\hline $\begin{array}{c}\text { Ex. } \\
\text { no }\end{array}$ & $\begin{array}{l}\text { Working gap } \\
(\mathrm{mm})\end{array}$ & $\begin{array}{c}\text { Workpiece speed } \\
\text { (rpm) }\end{array}$ & $\begin{array}{c}\text { Wheel speed } \\
(\mathrm{rpm})\end{array}$ & $\begin{array}{l}\text { Feed rate } \\
(\mathrm{mm} / \mathrm{rev})\end{array}$ & $\begin{array}{l}\text { Normal force } \\
(\mathrm{N})\end{array}$ & $\begin{array}{c}\mathrm{Ra} \\
(\mathrm{nm})\end{array}$ & $\begin{array}{c}\text { MRR } \\
(\mathrm{mg} / \mathrm{min})\end{array}$ \\
\hline 1 & 5 & 275 & 200 & 0.1 & 23.37 & 26 & 0.267 \\
\hline 2 & 5 & 275 & 200 & 0.15 & 23.41 & 18 & 0.314 \\
\hline 3 & 5 & 275 & 200 & 0.20 & 24.62 & 24 & 0.343 \\
\hline 4 & 5 & 300 & 250 & 0.1 & 19.28 & 30.5 & 0.195 \\
\hline 5 & 5 & 300 & 250 & 0.15 & 20.74 & 42 & 0.357 \\
\hline 6 & 5 & 300 & 250 & 0.20 & 21.69 & 24 & 0.200 \\
\hline 7 & 5 & 350 & 300 & 0.1 & 18.96 & 27 & 0.238 \\
\hline 8 & 5 & 350 & 300 & 0.15 & 20.24 & 33 & 0.305 \\
\hline 9 & 5 & 350 & 300 & 0.20 & 22.35 & 40.5 & 0.333 \\
\hline 10 & 10 & 275 & 250 & 0.1 & 16.75 & 38 & 0.248 \\
\hline 11 & 10 & 275 & 250 & 0.15 & 17.24 & 22.5 & 0.205 \\
\hline 12 & 10 & 275 & 250 & 0.20 & 19.52 & 21 & 0.290 \\
\hline 13 & 10 & 300 & 300 & 0.1 & 18.27 & 37.5 & 0.219 \\
\hline 14 & 10 & 300 & 300 & 0.15 & 18.92 & 39 & 0.267 \\
\hline 15 & 10 & 300 & 300 & 0.20 & 19.68 & 25.5 & 0.248 \\
\hline 16 & 10 & 350 & 200 & 0.1 & 19.05 & 30.5 & 0.186 \\
\hline 17 & 10 & 350 & 200 & 0.15 & 20.59 & 29 & 0.224 \\
\hline 18 & 10 & 350 & 200 & 0.20 & 22.16 & 26.5 & 0.262 \\
\hline 19 & 15 & 275 & 300 & 0.1 & 19.57 & 36 & 0.219 \\
\hline 20 & 15 & 275 & 300 & 0.15 & 22.42 & 28.5 & 0.245 \\
\hline 21 & 15 & 275 & 300 & 0.20 & 21.75 & 19 & 0.268 \\
\hline 22 & 15 & 300 & 200 & 0.1 & 20.68 & 22.5 & 0.257 \\
\hline 23 & 15 & 300 & 200 & 0.15 & 21.75 & 35 & 0.239 \\
\hline 24 & 15 & 300 & 200 & 0.20 & 23.15 & 31.5 & 0.305 \\
\hline 25 & 15 & 350 & 250 & 0.1 & 20.47 & 23.5 & 0.285 \\
\hline 26 & 15 & 350 & 250 & 0.15 & 19.84 & 34.5 & 0.291 \\
\hline 27 & 15 & 350 & 250 & 0.20 & 21.43 & 28 & 0.246 \\
\hline
\end{tabular}

fluent is accumulate the circular surface of a accumulate magnetic device by a hydraulic pumping system, which carries the fluid to the work zone surface. Stainless steel (SS 304L) work specimen issued for this surface finishing study. AISI 304L austenitic steel, having size of $200 \mathrm{~mm}$ diameter and $350 \mathrm{~mm}$ length is chosen as a work piece. Table. 3. Shows the chemical composition of (SS 304L) stainless steel. Initially, the work sample is completed by regular grinding. Tests were conducted at different levels of feed rate, wheel speed rotation, work piece rotation, and measurement of the natural and tangential emission response tool operating in the workplace.. Each experimental trail was performed for 12-15 minutes to obtain the better finish.

\section{RESULT \& DISCUSSION}

\section{A. Grey relational analysis}

Taguchi method is explains the optimal method parameter values for nano level finishing of austenite material of stainless steel. The parameters which are important is involved in this finishing operation are working gap (WG), workpiece speed (WS), wheel speed (WHS) and feed rate (FR). The parameters classified into three levels are presented in Table. 2.The experiment were investigate for the cylindrical finishing parameters by using approach of $L_{27}$ orthogonal array as in Table. 3. Following steps wereto be followed to find the optimal process parameters value.

Step 1: $\mathrm{S} / \mathrm{N}$ ratios data transformation

The output data is to be converted to $\mathrm{S} / \mathrm{N}$ rate. Calculating the $\mathrm{S} / \mathrm{N}$ rate formulas is below,

Better larger

$\eta=-10 \log _{10}\left(\frac{1}{n} \sum_{\mathrm{i}=1}^{\mathrm{n}} \mathrm{y}_{\mathrm{ij}}{ }^{2}\right)$

Step 2: For further analysis, a single input a transformation performed is Normalization to apportion data and scale it for adequate range.

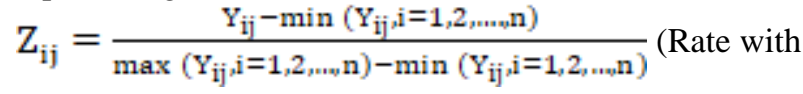

$$
\begin{aligned}
& \text { larger-better case) }
\end{aligned}
$$

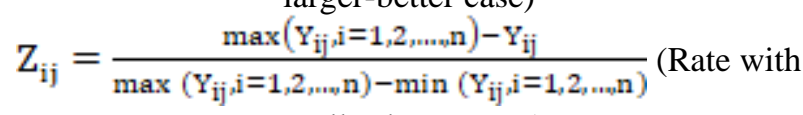

$$
\begin{aligned}
& \text { smaller-better case) }
\end{aligned}
$$

Step 3: Distribute S / N ratio values in Gray co-efficient (GC) calculation

$$
\mathrm{GC}_{\mathrm{ij}}=\frac{\Delta_{\min }+\lambda \Delta_{\max }}{\Delta_{\mathrm{ij}}+\lambda \Delta_{\max }}\left\{\begin{array}{l}
\mathrm{i}=1,2, \ldots, \mathrm{n} \text { - experiments } \\
\mathrm{j}=1,2, \ldots, \mathrm{m}-\text { responses }
\end{array}\right.
$$

$\mathrm{GC}_{\mathrm{ij}}$ - Grey relational co-efficient

$\Delta$ - difference b/w in $\mathrm{Y}_{0 \mathrm{j}}$ and $\mathrm{Y}_{\mathrm{ij}}$

$\mathrm{Y}_{0 \mathrm{j}}$ - optimum performance value

$\mathrm{Y}_{\mathrm{ij}}$ - jth response of ith normalized value

$\Delta_{\text {min }}$ - high value of $\Delta$

$\Delta_{\text {max }}$ high value of $\Delta$

$\lambda$ - distinctive co-efficient that range is $0 \leq \lambda \leq 1$

Step 4: Gauge grey relational grade $\left(\mathrm{G}_{\mathrm{i}}\right)$

$$
\mathrm{G}_{\mathrm{i}}=\frac{1}{\mathrm{~m}} \sum \mathrm{GC}_{\mathrm{ij}} \mathrm{m} \text { - Number of responses }
$$

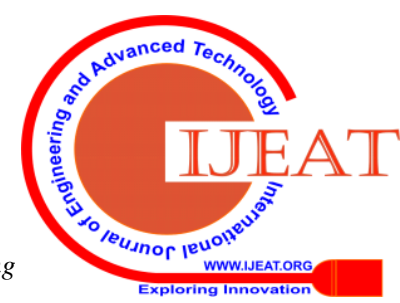




\section{Measurement of Process Parameters in Magneto-Rheological Fluid Assisted Cylindrical Surface Nano Finishing Process using Grey Relational Methods}

Step 5: choose excellent level for the factors depends on higher average $G_{i}$ through ANOVA method.

Table 4. Normalized values of $\mathrm{S} / \mathrm{N}$ ratio and grey grade.

\begin{tabular}{|c|c|c|c|c|c|c|c|c|c|}
\hline $\begin{array}{c}\text { Normal } \\
\text { force }(\mathrm{N})\end{array}$ & $\begin{array}{c}\mathrm{Ra} \\
(\mathrm{nm})\end{array}$ & $\begin{array}{c}\text { MRR } \\
\text { (mg/min) }\end{array}$ & $\begin{array}{c}\text { S/N rate Fn } \\
(\mathrm{N})\end{array}$ & $\begin{array}{c}\text { S/N rate } \mathrm{Ra} \\
(\mathrm{nm})\end{array}$ & $\begin{array}{c}\mathrm{S} / \mathrm{N} \text { rate MRR } \\
\text { (mg/min) }\end{array}$ & $\begin{array}{l}\text { Normalized S/N } \\
\text { ratio Fn }\end{array}$ & $\begin{array}{c}\text { Normalized S/N } \\
\text { ratio Ra }\end{array}$ & $\begin{array}{c}\text { Normalized S/N } \\
\text { ratio MRR }\end{array}$ & $\left(G_{i}\right)$ \\
\hline 23.37 & 26 & 0.267 & 27.37317 & 28.29946 & -11.46977 & 0.135074 & -2.193983 & 8.87156 & 0.62912 \\
\hline 23.41 & 18 & 0.314 & 27.38802 & 25.10545 & -10.06140 & 0.130634 & -1.63753 & 8.44113 & 0.65460 \\
\hline 24.62 & 24 & 0.343 & 27.82576 & 27.60422 & -9.29411 & -0.00022 & -2.07286 & 8.20663 & 0.58434 \\
\hline 19.28 & 30.5 & 0.195 & 25.70214 & 29.68599 & -14.19930 & 0.63463 & -2.43553 & 9.70577 & 0.82808 \\
\hline 20.74 & 42 & 0.357 & 26.33617 & 32.46498 & -8.94663 & 0.44508 & -2.91968 & 8.10043 & 0.68245 \\
\hline 21.69 & 24 & 0.2 & 26.72519 & 27.60422 & -13.97940 & 0.32879 & -2.07286 & 9.63856 & 0.71299 \\
\hline 18.96 & 27 & 0.238 & 25.55676 & 28.62727 & -12.46846 & 0.67809 & -2.25109 & 9.17679 & 0.85237 \\
\hline 20.24 & 33 & 0.305 & 26.12421 & 30.37027 & -10.31400 & 0.50845 & -2.55475 & 8.51833 & 0.73657 \\
\hline 22.35 & 40.5 & 0.333 & 26.98555 & 32.14910 & -9.55111 & 0.25095 & -2.86465 & 8.28518 & 0.61819 \\
\hline 16.75 & 38 & 0.248 & 24.48029 & 31.59567 & -12.11096 & 0.99991 & -2.76823 & 9.06753 & 0.66817 \\
\hline 17.24 & 22.5 & 0.205 & 24.73074 & 27.04365 & -13.76492 & 0.92503 & -1.97520 & 9.57302 & 0.94974 \\
\hline 19.52 & 21 & 0.29 & 25.80959 & 26.44438 & -10.75204 & 0.60251 & -1.87079 & 8.65221 & 0.82358 \\
\hline 18.27 & 37.5 & 0.219 & 25.23477 & 31.48062 & -13.19111 & 0.77435 & -2.74819 & 9.39765 & 0.89131 \\
\hline 18.92 & 39 & 0.267 & 25.53842 & 31.82129 & -11.46977 & 0.68358 & -2.80754 & 8.87156 & 0.82210 \\
\hline 19.68 & 25.5 & 0.248 & 25.88050 & 28.13080 & -12.11096 & 0.58131 & -2.16459 & 9.06753 & 0.96336 \\
\hline 19.05 & 30.5 & 0.186 & 25.59789 & 29.68599 & -14.60974 & 0.66579 & -2.43553 & 9.83121 & 0.84726 \\
\hline 20.59 & 29 & 0.224 & 26.27312 & 29.24795 & -12.99503 & 0.46393 & -2.35922 & 9.33772 & 0.74413 \\
\hline 22.16 & 26.5 & 0.262 & 26.91139 & 28.46491 & -11.63397 & 0.27312 & -2.22280 & 8.92175 & 0.67142 \\
\hline 19.57 & 36 & 0.219 & 25.83181 & 31.12605 & -13.19111 & 0.59586 & -2.68641 & 9.39765 & 0.79038 \\
\hline 22.42 & 28.5 & 0.245 & 27.01271 & 29.09689 & -12.21667 & 0.24283 & -2.33290 & 9.09984 & 0.65904 \\
\hline 21.75 & 19 & 0.268 & 26.74918 & 25.57507 & -11.43730 & 0.32161 & -1.71935 & 8.86164 & 0.71894 \\
\hline 20.68 & 22.5 & 0.257 & 26.31101 & 27.04365 & -11.80133 & 0.45261 & -1.97520 & 8.97290 & 0.75439 \\
\hline 21.75 & 35 & 0.239 & 26.74918 & 30.88136 & -12.43204 & 0.32161 & -2.64379 & 9.16566 & 0.67160 \\
\hline 23.15 & 31.5 & 0.305 & 27.29101 & 29.96621 & -10.31400 & 0.15963 & -2.48435 & 8.51833 & 0.61295 \\
\hline 20.47 & 23.5 & 0.285 & 26.22235 & 27.42135 & -10.90310 & 0.47911 & -2.04100 & 8.69838 & 0.75568 \\
\hline 19.84 & 34.5 & 0.291 & 25.95083 & 30.75638 & -10.72214 & 0.56028 & -2.62201 & 8.64307 & 0.76039 \\
\hline 21.43 & 28 & 0.246 & 26.62044 & 28.94316 & -12.18129 & 0.36010 & -2.30612 & 9.08902 & 0.70096 \\
\hline
\end{tabular}

The experiment calculation is done about $\mathrm{S} / \mathrm{N}$ ratio and the values of the grey grade $(\mathrm{G})$ and tabulated in Table 5. S / N ratio for friction welding at each stage is summarized in
Table 6, which summarizes the effect of the assigned S / N ratio at each stage of the erosion fusing method. These tables evaluated from orthogonal array $\mathrm{S} / \mathrm{N}$ ratio values.

Table 5. Results for ANOVA for cylindrical finishing parameters

\begin{tabular}{|l|l|l|l|l|l|l|}
\hline $\begin{array}{c}\text { Cylinder finishing } \\
\text { parameters }\end{array}$ & DF & SS & MS & F & P-value & \% contribution \\
\hline WG & 2 & 0.33365 & 0.16683 & 5.50 & 0.044 & 33.54 \\
\hline WS & 2 & 0.04171 & 0.02085 & 0.69 & 0.538 & 4.19 \\
\hline WLS & 2 & 0.13852 & 0.06926 & 2.28 & 0.183 & 13.93 \\
\hline FR & 2 & 0.02311 & 0.01155 & 0.38 & 0.699 & 2.32 \\
\hline WG*FR & 4 & 0.04914 & 0.01228 & 0.41 & 0.799 & 4.94 \\
\hline WS*FR & 4 & 0.12090 & 0.03022 & 1.00 & 0.477 & 12.15 \\
\hline WLS*FR & 4 & 0.10580 & 0.02645 & 0.87 & 0.532 & 10.64 \\
\hline Error & 6 & 0.18192 & 0.03032 & & & 18.29 \\
\hline Total & 26 & 0.99475 & & & & 100 \\
\hline
\end{tabular}

Table 6. The S/N table for cylindrical surface finishing parameters

\begin{tabular}{|l|l|l|l|}
\hline Parameters & Level 1 & Level 2 & Level 3 \\
\hline $\begin{array}{l}\text { Working } \\
\text { gap(A) }\end{array}$ & $\mathbf{0 . 6 9 9 9}$ & 0.9423 & 0.7138 \\
\hline $\begin{array}{l}\text { Workpiece } \\
\text { speed(B) }\end{array}$ & 0.7753 & 0.8377 & $\mathbf{0 . 7 4 3 0}$ \\
\hline $\begin{array}{l}\text { Wheel } \\
\text { speed(C) }\end{array}$ & $\mathbf{0 . 6 8 5 5}$ & 0.8202 & 0.8503 \\
\hline Feed rate(D) & 0.8241 & $\mathbf{0 . 7 5 3 4}$ & 0.7785 \\
\hline \multicolumn{2}{|l|}{ Optimal setting parameters: $\mathrm{A}_{1} \mathrm{~B}_{3} \mathrm{C}_{1} \mathrm{D}_{2}$} \\
\hline
\end{tabular}

\section{B. Analysis of Variance (ANOVA)}

Audit the causes of Categorical Factors (CF) on response using ANOVA technique and it is used to get important values of tensile strength, and impact strength. It decays the unpredictability in the response variable along with the various factors. It depends on the analysis type which may be necessary to check the suitable factors and a large amount of response variability is allocated to each factor. To establish the important factor that give additional nearer to the output performance of ANOVA. It is responsible for dividing the absolute variable measured into the dependent variable into its resources. A total measured variance value is completely variation of total which attained from participants. A dependent measure reveals the output of the study as output variables and makes valuable way to conceive/envision it. 


\section{Measurement of Process Parameters in Magneto-Rheological Fluid Assisted Cylindrical Surface Nano Finishing Process using Grey Relational Methods}

Factors that influence the dependent variable are input factors, effects of treatment and conditions of treatment and these are reflected by independent variable because of these two variables are closely related with each of them. For investigation the ANOVA is carried out for which cylindrical surface finishing parameters like wheel speed, WPS, feed rate and working gap. Results of ANOVA for these parameters are evaluated using $\mathrm{S} / \mathrm{N}$ response tables. Effects of Individual and interactive factors importance is evaluated. It is suitable for all types which reveal the high contribution nearer to the rough surface of the material.

\section{Optimal parameters for better surface roughness}

$\mathrm{S} / \mathrm{N}$ ratio of the finishing parameter is high and it is considered as best for the parameters. The higher values consequent is representing in boldface for every factor. From $\mathrm{S} / \mathrm{N}$ table, three cases of weightage is considered and it is observe that the level of the forecast cylindrical finishing parameters is $A_{1} B_{3} C_{1} D_{2}$ that is working gap (WG) $=5 \mathrm{~mm}$, workpiece speed $(\mathrm{WS})=350 \mathrm{rpm}$; wheel speed $(\mathrm{WHS})=200$ $\mathrm{rpm}$; feed rate $(\mathrm{FR})=0.15 \mathrm{~mm} / \mathrm{rev}$.
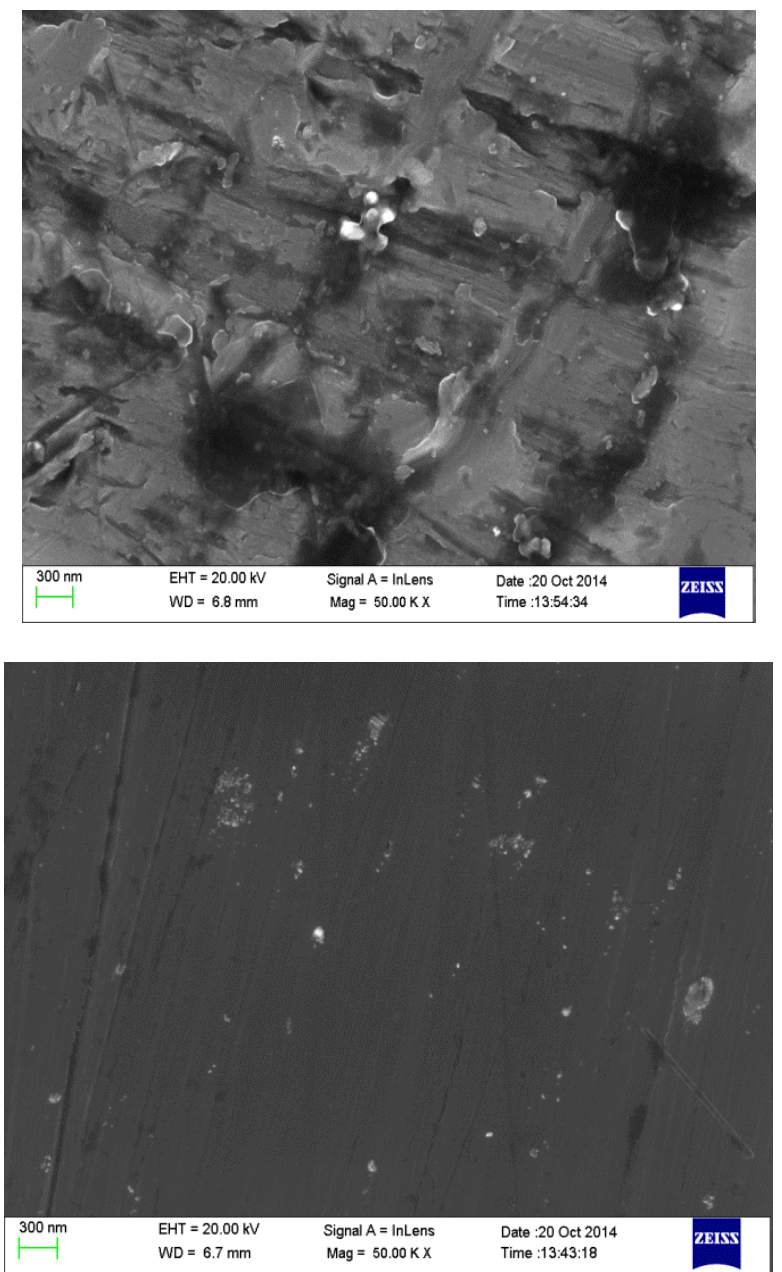

Figure. 2. Scanning electron microscope image (SEM) (a) without MR fluid finished workpiece at $300 \mathrm{~nm}$ level. (b) MR fluid finihsed workpiece at $300 \mathrm{~nm}$ level.
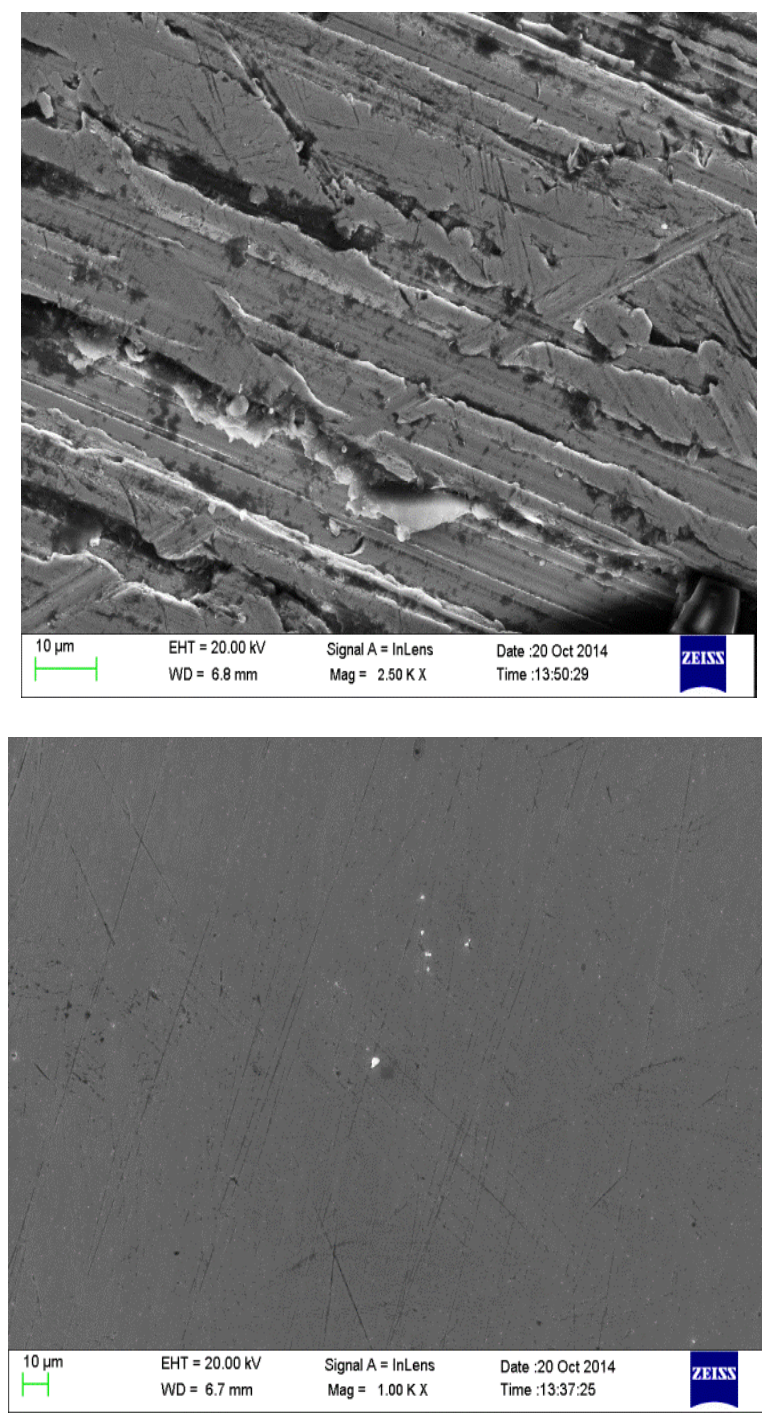

Figure.3 scanning electron microscope (SEM) image (a). without MR fluid finished workpiece at $10 \mu \mathrm{m}$ level. (b). MR fluid finihsed workpiece at $\mathbf{1 0} \boldsymbol{\mu m}$ level.
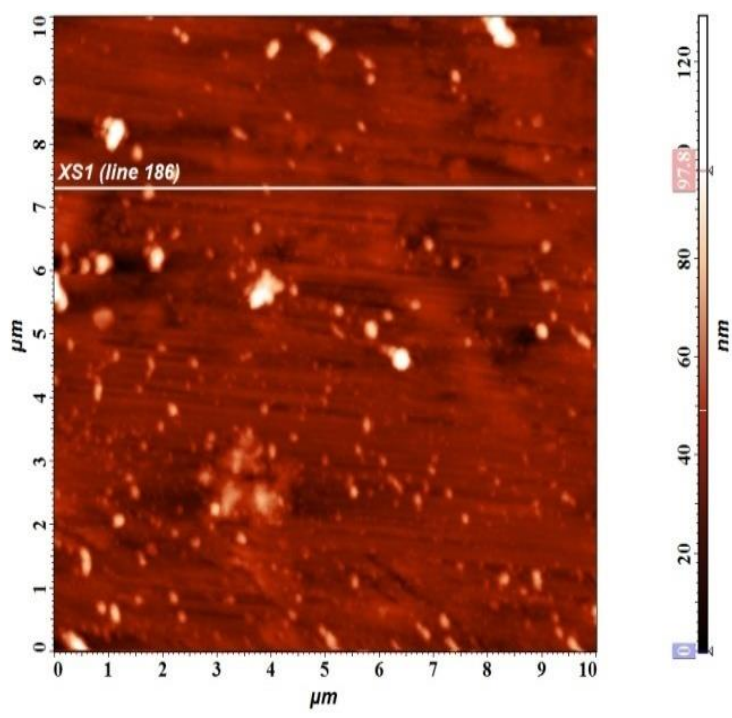


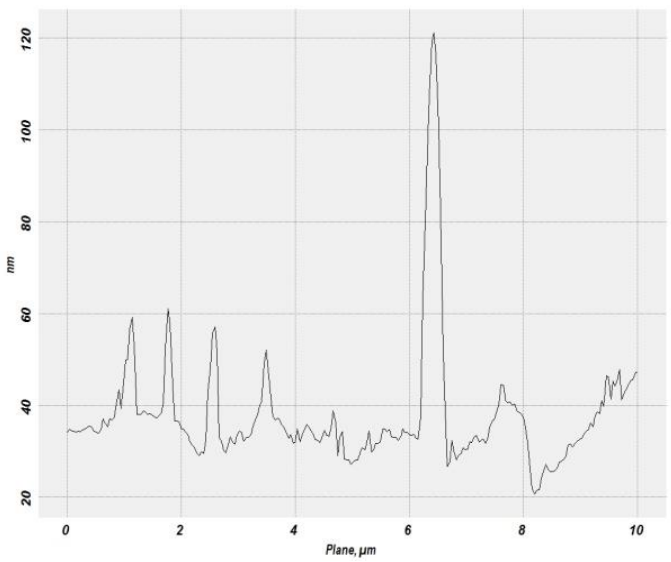

Figure. 4 Atomic force microscopic image of (a) 304L stainless steel without MR fluid finished surface (b) Cross sectional view.
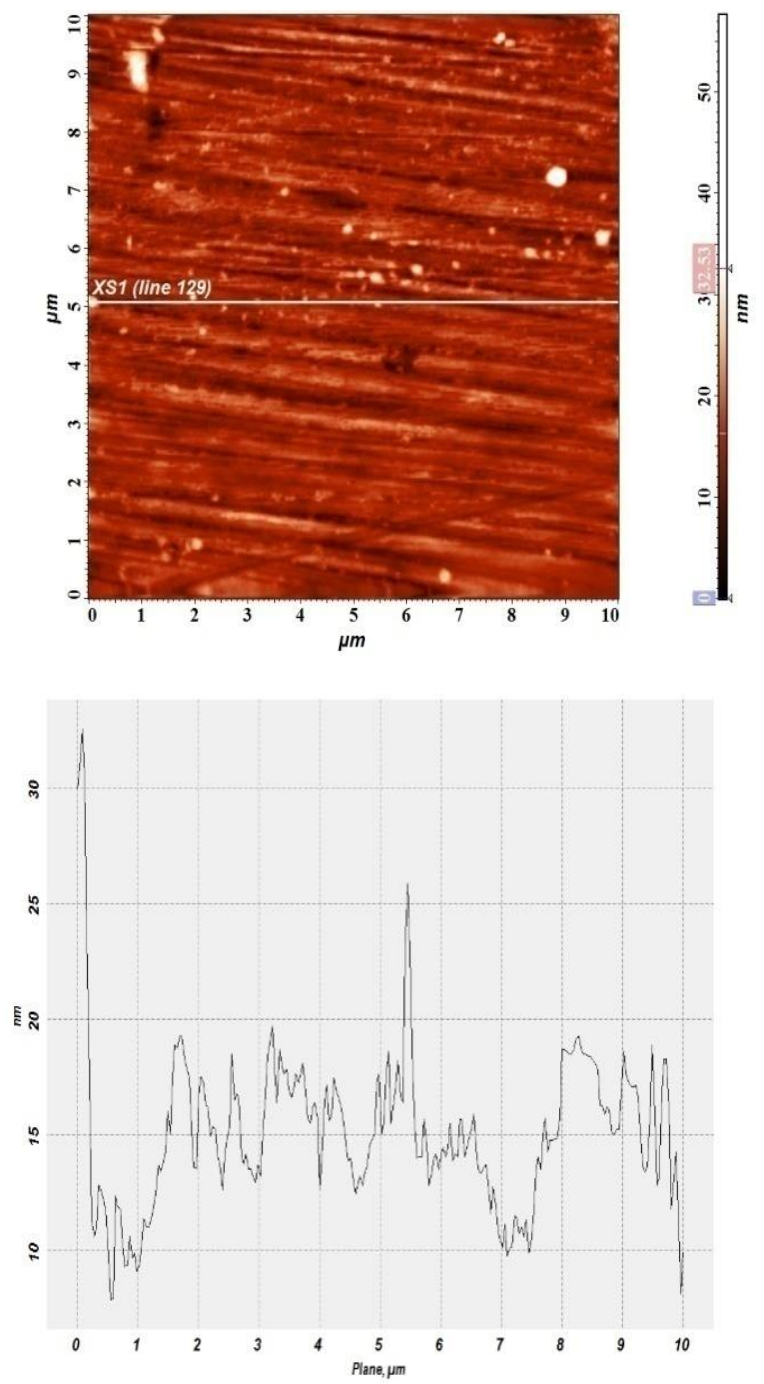

Figure. 5.Atomic force microscopic image of (a) 304L stainless steel with MR fluid finished surface. (b) Cross sectional view.

\section{FESEM and AFM micro structural study.}

MR fluid assisted cylindrical surface finishing of 304L stainless steel material is evaluated and micro structural examination done under the standard metallographic procedure is shown in Figures. 2, 3,4,5 and 6.
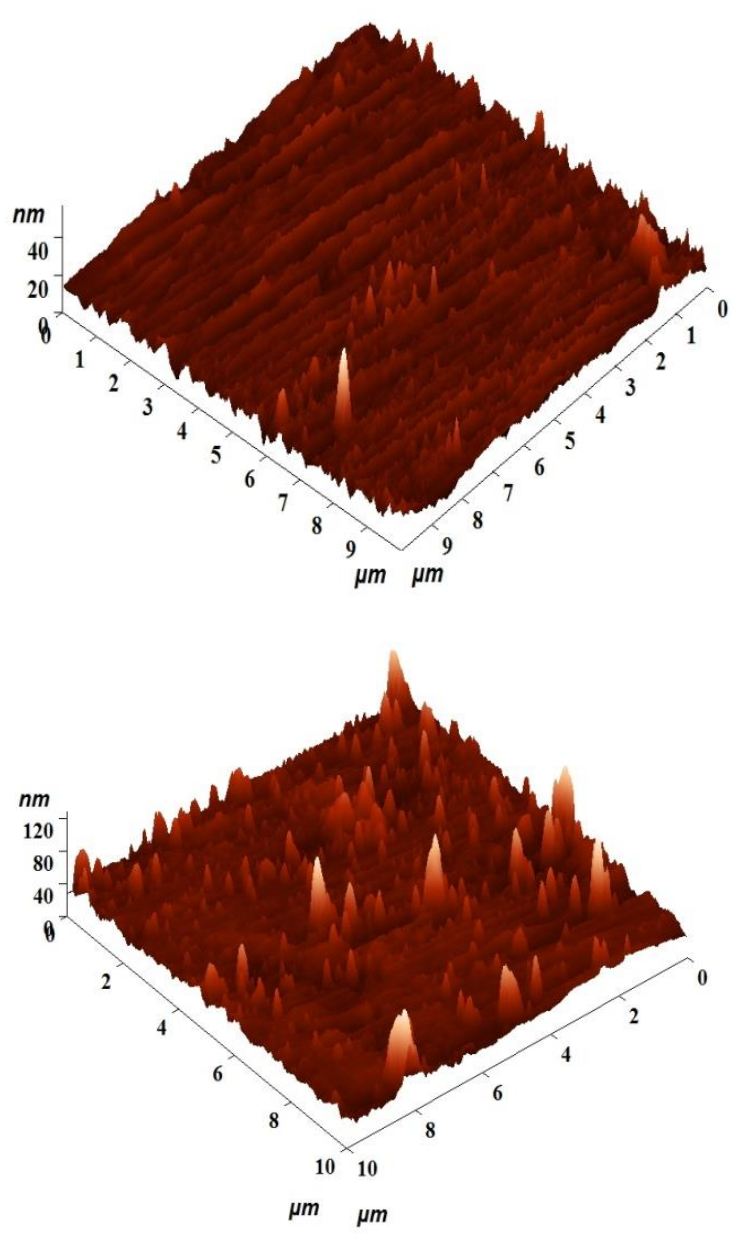

Figure 6. Topography of (A) MR fluid finished surface (B) without MR fluid finished surface.

The cylindrical finishing topography in 3D of final surfaces are appeared in figure (A) and figure (B). The exp.no.3 shows that the surface roughness value about $18 \mathrm{~mm}$ which is obatained as minimum and it reveals that finishing of MRF process AISI 304L stainless steel done by the parameters with proper combination and the 304L SS without MR fluid is around $100 \mathrm{~nm}$ to $50-120 \mathrm{~nm}$. Therefore, surface roughness of significant reduction is achieved. Thus, in this study the roughness reduction of surface is achieved.

\section{CONCLUSION}

This experimental verification is reveals the process parameter effects through carrier wheel speed, workpiece speed, working gap and feed rate for finishing 304L stainless steel by cylindrical MR fluid finishing method. The $\mathrm{Ra}$ is suffered by feed rate as well as work piece speed.

MRR increases with increasing the concentration of CIPs and the also carrier wheel speed is increased while MRR decrease and in an optimum level the abrasive concentration past is also increased. In the instant study the low coarseness of surface about $4 \mathrm{~nm}$ is achieved. The selection study is done with the independent parameters which are in the particular range. The carrier wheel speed, working gap, WPS and the feed rate used to minimize and maximize the final $\mathrm{Ra}$ and maximize MRR respectively. 


\section{Measurement of Process Parameters in Magneto-Rheological Fluid Assisted Cylindrical Surface Nano Finishing Process using Grey Relational Methods}

\section{REFERENCES}

1. Lohithaksha M Maiyar a*, Dr.R.Ramanujam b , K.Venkatesan c , Dr.J.Jerald, "Optimization of Machining Parameters for End Milling of Inconel 718 Super Alloy Using Taguchi Based Grey Relational Analysis" Procedia Engineering 64 (2013) 1276 - 1282

2. P. Jayaraman a *, L. Mahesh kumar,” Multi-response Optimization of Machining Parameters of Turning AA6063 T6 Aluminium Alloy using Grey Relational Analysis in Taguchi Method” Procedia Engineering 97 (2014) $197-204$.

3. Zahid A. Khan a *, Arshad N. Siddiquee a , Noor Zaman Khan a , Urfi Khan b , G. A. Quadir,” Multi response optimization of Wire electrical discharge machining process parameters using Taguchi based Grey Relational Analysis.Procedia Materials" Science 6 (2014) 1683 - 1695

4. J.B. Saedon, NorkamalJaafar, MohdAzmanYahay, NorHayatiSaad and MohdShahirKasim," Multi-objective optimization of titanium alloy through orthogonal array and grey relational analysis in WEDM". Procedia Technology 15 (2014) 833 - 841

5. Sunil Jha, V. K. Jain. RangaKomanduri, "Effect of extrusion pressure and number of finishing cycles on surface roughness in magnetorheological abrasive flow finishing (MRAFF) process" Int J AdvManufTechnol (2007) 33: 725-729

6. Ajay Sidpara, V.K. Jain, "Theoretical analysis of forces in magnetorheological fluid based finishing process". International Journal of Mechanical Sciences 56 (2012) 50-59.

7. Ajay Sidpara and V.K. Jain, "Nano-level finishing of single crystal silicon blank using magnetorheological finishing process". Tribology International 47 (2012) 159-166

8. Shai N. Shafrir, John. C. Lambropoulos, Stephen D. Jacobs, "A magnetorheological polishing-based approach for studying precision micro ground surfaces of tungsten carbides". Precision Engineering 31 (2007) 83-93

9. Kyung-In Jang, Doo-Yeon Kim, SangjinMaeng, Wonkyun Lee, Jungjin Han, JongwonSeok, Tae-Jin Je, Shinill Kang, Byung-Kwon Min, "Deburringmicroparts using a magnetorheological fluid". International Journal of Machine Tools \& Manufacture 53 (2012) 170-175.

10. H.B. Cheng, Y.P. Feng, L.Q. Ren, Suet To b , Y.T. Wang, Material removal and micro-roughness in fluid-assisted smoothing of reaction-bonded silicon carbide surfaces. Journal of Materials Processing Technology 209 (2009) 4563-4567

11. H.B. Cheng a, Yeung Yam b , Y.T. Wang, "Experimentation on MR fluid using a 2-axis wheel tool". Journal of Materials Processing Technology 209 (2009) 5254-5261

12. V.K. Jain, P. Ranjan b , V.K. Suri b , R. Komanduri, "Chemo-mechanical magneto-rheological finishing (CMMRF) of silicon for microelectronics applications". CIRP Annals Manufacturing Technology 59 (2010) 323-328

13. F.C. Tsai, B.H. Yan, C.Y. Kuan, F.Y. Huang, A Taguchi and "Experimental investigation into the optimal processing conditions for the abrasive jet polishing of SKD61 mold steel”. International Journal of Machine Tools \& Manufacture 48 (2008) 932-945.

14. Jae-SeobKwak, "Enhanced magnetic abrasive polishing of non-ferrous metals utilizing a permanent magnet". International Journal of Machine Tools \& Manufacture 49 (2009) 613-618.

15. Ajay Sidpara, V.K. Jain, "Experimental investigations into forces during magnetorheological fluid based finishing process". International Journal of Machine Tools \& Manufacture 51 (2011) 358-362

16. N. Senthilkumar, T. Tamizharasan b, V. Anandakrishnan, "Experimental investigation and performance analysis of cemented carbide inserts of different geometries using Taguchi based grey relational analysis" Measurement 58 (2014) 520-536.

17. Sadiq, M.S. Shunmugam, "A novel method to improve finish on non-magnetic surfaces in magneto-rheological abrasive honing process.’Tribology International 43 (2010) 1122-1126.

18. Mamilla Ravi Sankar, J. Ramkumar, V.K. Jain, "Experimental investigation and mechanism of material removal in nano finishing of MMCs using abrasive flow finishing (AFF) process". Wear 266 (2009) 688-698

19. Ajay Sidpara, V.K. Jain, "Nano-level finishing of single crystal silicon blank using magnetorheological finishing process". Tribology International 47 (2012) 159-166

\section{AUTHORS PROFILE}

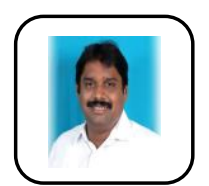

L.Prabhu Professor, Department of Mechanical Engineering, Aarupadai veedu Institute of Technology, Vinayaka Mission's Research Foundation, Chennai, India. prabhu@avit.ac.in

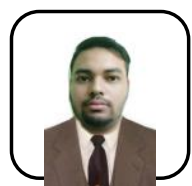

ChandanJyotiPatra - PG Scholar Department of Mechanical Engineering, Aarupadai veedu Institute of Technology, Vinayaka Mission's Research Foundation, Chennai, India. Chandanjyotipatr121@gmail.com

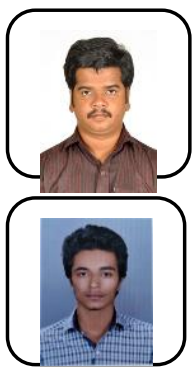

Mr.Raj Jawahar, Entrepreneur of Dynamechz Research Labz, India

Jishnu P Sajeev, UG Scholar, Department of Mechanical Engineering, Aarupadai veedu Institute of Technology, Vinayaka Mission's Research Foundation, Chennai, India

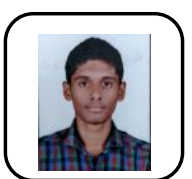

Dildas - UG Scholar, Department of Mechanical Engineering, Aarupadai veedu Institute of Technology, Vinayaka Mission's Research Foundation, Chennai, India

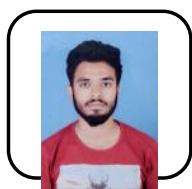

Mohammed Anas, UG Scholar Department of Mechanical Engineering, Aarupadai veedu Institute of Technology, Vinayaka Mission's Research Foundation, Chennai, India 